\title{
Hâkim Rüzgâr Yönünün Belirlenmesi İçin Bir Yazılım Önerisi: PrevailingWindRUB 1.0
}

\section{Software Proposal for Determining the Prevailing Wind Direction: PrevailingWindRUB 1.0}

\author{
Sedat $\mathrm{AVCI}^{1}$ (1) \\ 'İstanbul Üniversitesi, Edebiyat Fakültesi, Coğrafya Bölümü, İstanbul, Türkiye
}

ORCID: S.A. 0000-0003-4371-5578

\section{öz}

Bir yerin iklim elemanlarına ait özelliklerin bilinmesi, mekânsal çalışmalarda büyük öneme sahiptir. İklim elemanlarından rüzgâr, sıcaklık ve yağış kadar sık kullanılmasa da özellikle planlama çalışmalarında yönlendirici olma özelliğine sahiptir. Genel atmosfer sirkülasyonuna bağlı olarak zemine yakın hava kütlelerinin yer değiştirmesi şeklinde tanımlanan rüzgâr, büyük ölçüde yatay yönde bir harekettir. Rüzgârın yönü, hızı (şiddeti) ve esiş sıklığı (frekansı) en belirgin üç özelliğini oluşturmaktadır. Hâkim rüzgâr yönünün belirlenmesi ve gösteriminde temel olarak rüzgârın hangi yönden kaç kez estiği esas alınmaktadır. Rüzgâr rasatları 8 veya 16 yöne göre ifade edilmektedir. Gerçekte ise hâkim rüzgâr yönü daha farklı olabilir. Hâkim rüzgâr yönünün açı cinsinde ortaya konulması, gerçeğe daha yakın sonuçları yansıtacaktır. Rubinstein, rüzgârın hangi yönden ne kadar sıklıkla estiğini esas alınarak hâkim rüzgâr yönü derece cinsinden belirlenebileceğini ifade etmektedir. Önerilen yöntemde, her yöne ait esme sayılarının toplam içindeki oranı kullanılmaktadır. Bu işlemi yaparken aynı zamanda farklı yönlere ait paylar ile de belli ilişkilerin göz önüne alınması, yöntemi diğer yöntemlere nazaran daha avantajlı hale getirmektedir. Yöntemde sakin günlere ait veriler ise kullanılmamaktadır. Ayrıca varsa ikinci dereceden hâkim rüzgâr yönünü ve frekansını da göstermesi Rubinstein metodunu öne çıkarmaktadır. Makale ekindeki yazılım, Rubinstein yöntemiyle hâkim rüzgâr yönünün belirlenmesi için önerilmiştir.

Anahtar kelimeler: Esiş sıklığı, Rubinstein, rüzgâr yönü

\section{ABSTRACT}

Knowing the characteristics of the climatic elements of a place is greatly important in spatial studies. Although not used as often as temperature and precipitation, wind might be utilized as a guide especially in planning studies. Wind is mostly a horizontal movement. The direction, speed and frequency of the wind are its three most prominent characteristics. Establishing the prevailing wind direction in terms of angle will provide more realistic results. Rubinstein stated that the prevailing wind direction can be determined in degrees based on how often the wind blows from which direction. The ratio of the directions from which the wind blows to all directions is used in the proposed method. While doing so, considering certain relations with the shares belonging to different directions at the same time makes this method more advantageous over others. The method does not use data on calm days, but shows the second-order prevailing wind direction and frequency if available. The software attached used herein is proposed to determine the prevailing wind direction using the Rubinstein method.

Keywords: Frequency, Rubinstein, wind direction 


\section{EXTENDED ABSTRACT}

Knowing the characteristics of climatic elements is greatly significant in spatial studies. Although not used as often as temperature and precipitation, wind can be a guide, especially in planning studies. Wind is the displacement of air masses close to the ground, which depends on the general atmospheric circulation. It is mostly a horizontal movement. The wind direction, speed, and frequency are the three most prominent characteristics. The main representation of the prevailing wind direction is based on how many times the wind blows from a certain direction.

Various methods are used to determine the prevailing wind direction. The easiest method is to draw a windmill based on wind counts. Wind observations are expressed according to 8 or 16 directions, but in reality, the prevailing wind direction may be different. Determining the prevailing wind direction in terms of angle will reflect more realistic results. One of the various methods developed is the geometric method.

The geometric method is based on the windmill formation and determines the resultant force of the two branches of a windmill in a clockwise direction starting from the north. In this method, the windmill branches must be formed according to a scale proportional to the number of blows. As a drawback, however, this method causes difficulties in showing the directions where the number of blows is low and is insufficient to reflect the truth. Therefore, it is not of much use. Using formulas is much more common in determining the prevailing wind directions. The formula developed by Lambert is not preferred because its use and expression of the results are unclear. In contrast, the formula developed by Rubinstein for determining the prevailing wind direction gives more realistic results.

The Rubinstein method is different from others because it includes the direction of the most blowing wind and other directions in the calculation and uses the ratio of these numbers in the total. It also shows the second-order wind direction, if any, and determines the percentages of the prevailing wind direction(s). The drawback of the method is that it is based on the blow number, not the blow time. Long annual average values of the fly directions are used in the Rubinstein method.

Basics of the Rubinstein method: This method is based on the blowing numbers of the wind. Rubinstein stated that the number of blows in successive directions must have a certain pattern for the prevailing wind to form. For this purpose, the percentage of blow numbers belonging to each direction is first found. Next, a sequence is created, provided that the third term is greater than the first term; the second term is greater than the fourth term; and the sum of the second and third terms is at least $25 \%$.

Sequence formation indicates that only one prevailing wind direction exists. The formation of two sequences indicates a second-order wind direction. The absence of a sequence formation indicates that the prevailing wind direction does not appear. In the presence of a sequence formation, the following formula is used to find the prevailing wind direction from the beginning of the sequence:

$$
x_{\max }=1+\frac{n 3-n 1}{(n 3-n 1)+(n 2-n 4)}
$$

The multiplication of the number obtained by 45 shows how many degrees the prevailing wind direction is from the clockwise direction from the beginning of the sequence. The frequency of the prevailing wind direction is obtained as follows:

$$
\varphi\left(x_{\max }\right)=n 2+n 3+\frac{(n 3-n 1)+(n 2-n 4)}{2} \cdot\left(\frac{3}{2}-x_{\max }\right)^{2}
$$

The program performs these calculations and prints direct results.

\section{Use of PrevailingWindRUB 1.0 software}

The wind data are prepared according to international standards in 16 directions. In the DATA tab, the number of blows for each direction is entered in the relevant cells. The Rubinstein method performs a calculation according to eight directions. If your data set belongs to eight directions, you must use the table where you can enter values for eight directions in the relevant part of the same tab. In the RESULT tab, if monthly data are entered, the prevailing monthly, seasonal, and annual wind directions are expressed in terms of frequency and angle in percentage. If daily or other period data are entered, values are provided for the prevailing wind direction in the row with the entered data. The graphics are in tabs starting with " $G$ ". 


\section{GİRIŞ}

Bir yerin iklim elemanlarına ait özelliklerin bilinmesi, mekânsal çalışmalarda büyük öneme sahiptir. Sıcaklık ve yağışa ait ortalamaların yanında ekstrem değerler, bu değerlerin sıklıkları ve eğilimleri mekânın özelliklerinin ortaya konulmasında yol göstericidir. İklim elemanlarından rüzgâr, sıcaklık ve yağış kadar sık kullanılmasa da özellikle planlama çalışmalarında yönlendirici olma özelliğine sahiptir. Örnek olarak hâkim rüzgârlara paralel vadilerde ideal bir planlama için; yoğun ve dar sokakların yerleşim düzeni, gölgeli kaldırımların ve kısa yürüyüş mesafelerinin belirlenmesi, yeşil alanlar ile yüksek albedoya sahip yüzey malzemelerinin binaların cephe kaplamasında kullanılması gibi unsurları içermesi gerektiğine vurgu yapılmaktadır (Thompson ve Perry, 1997, s. 184). Bunun yanında sıcaklığın ve nemin dağılışında (Lamb, 2011, s. 62), kuraklık, yangınlar, kar erimesi, vejetasyon devresinin erken veya geç başlaması vb (Olivier, 2005, s. 467), bitkilerin tohumlarının dağılışı (Avc1, 2016, s. 119) veya bitkilerin dal ve sürgünlerinin zarar görmesi, ağaçlarda şekil bozuklukları ile evapotranspirasyonu arttırmas1 (Avc1, 1998, s. 188) gibi olaylarda da rüzgâr etkili olmaktadır.

Genel atmosfer sirkülasyonuna bağlı olarak zemine yakın hava kütlelerinin yer değiştirmesi şeklinde tanımlanan rüzgâr, büyük ölçüde yatay yönde bir harekettir. Hava kütlesinin bu hareketi ancak çevresine yaptığı etkilerle gözlenebilir. Rüzgârın yönü, hızı (şiddeti) ve esiş sıklığı (frekansı) en belirgin üç özelliğini oluşturmaktadır (Erol, 1999, s. 123). Hava kütlelerinin hareketi atmosfer sirkülasyonun sonucu olarak ortaya çıksa da belirli dönemlerde tekrarlayan bölgesel veya yerel hava akımları da vardır. Bunlar mevsimlik veya gün içindeki sıcaklık farklılaşmasına bağlı olarak gerçekleşebilir. $\mathrm{Bu}$ rüzgârların oluşumunda topografya, deniz vb unsurlar önemli etkenlerdir. Yerel koşullar genel hâkim rüzgâr yönü dışında daha az etkili olan, fakat tekrarlayan rüzgârların meydana gelmesine yol açar. Fön, meltem vb bu tür rüzgârlara örnek oluşturmaktadır (Balling, Jr ve Cerveny, 2005, s. 815 vd).

Meteoroloji ve klimatolojideki birçok teorik ve uygulamaya yönelik problemin çözümü, rüzgâr hızı, yönü ve/veya rüzgârın esiş sıklığının doğru ölçülmesini gerektirir. Teorik bir bakış açısıyla hava hareketinin kuvvetleri, yasaları ve etkilerinin incelenmesi atmosfer bilimlerinin temelini oluşturmaktadır (Balling, Jr ve Cerveny, 2005, s. 819). Yapılan çalışmalardan bazıları yüksek atmosferdeki hava kütlelerinin hareketleri ile ilgilidir. Hava kütlelerinin hareketinde etkili olan faktörlerin değerlendirilmesine ilişkin modeller yakın yıllarda daha çok kullanılır olmuştur. Rüzgâr ile ilgili çalışmaların yöneldiği diğer konu rüzgârın hızı ve hızın zaman içindeki değişimi üzerinedir. Bu çalışmalardan küresel ölçekte olanlarında, hava akımlarının modellenmesi gerçekleştirilmekte, bir kısmın da ise olası iklim değişikliğinin sonuçları üzerine çıkarımlarda bulunulmaktadır. Rüzgâr gözlemlerini gerektiren uygulamaya yönelik örnek çalışmalardan da söz etmek mümkündür.

Rüzgârın yönü genel atmosfer hareketlerine bağlı olarak ortaya çıkar ancak bu hareketi bozan veya değiştiren etkilerden de söz etmek mümkündür. Yerel olarak rüzgâr hızındaki değişime etki eden faktörlerden bazıları kısa sürelerde değişiklik göstermezler ve ölçümlerde sabit kabul edilirler. Dağ, tepe ve vadi gibi yüzey şekillerini içeren topografya, orman, mera veya çıplak kayalık bir yüzey olma ile açıklanan pürüzlülük ve yüksek bina gibi engeller sabit unsurlara örnek gösterilebilir. Bazı veriler ise anlık koşullara bağlı olarak ortaya çıkmaktadır. Başlıca örnekleri atmosferik kararlılıktaki değişim, yerel sıcaklık değişimleri, deniz meltemleri ve anabatik veya katabatik dağ rüzgârları gibi unsurlardır. Sabit ve değişken unsurlar rüzgâr hızı belirlenmesinde önemli rol oynamaktadır (Balley, 2005, s. 492; Munro, 2005, s. 440; Langreder, 2010, s. 49; Tong, 2010, s. 6; Türksoy, 2001, s. 92-93).

Herhangi bir sanayi tesisinin yerinin belirlenmesinden ulaşıma, bir yerleşmenin planlanmasından, binaların yerleşim durumuna kadar değişen farklı durumlar için de rüzgâr özelliklerinin bilinmesi gerekir. Benzer durum havacılık, deniz ulaşımı ve hatta tarım alanlarının planlanması açısından da önem taşımaktadır (Allisow, Drostov ve Rubinstein, 1956, s. 469-470). Özellikle ulaşım araçlarının hızlanmasına bağlı olarak, karayolu ve demiryolu ulaşımında rüzgârın esme hızı, yönü ve frekansı açısından önemini daha da artırdığını söylemek yerinde olacaktır. Son yıllarda gerçekleştirilen uygulamaya yönelik çalışmalar arasında rüzgâr gözlemlerinden faydalanarak; atmosferik kirleticilerden oluşan emisyon kaynaklarının konumlandırılması, optimum havalandırma için evlerin tasarımı, böcek veya hastalıkların hava yoluyla yayılımı gibi çalışmalar gerçekleştirilmekte, hatta rüzgârın etkili olduğu yer şekillerinin analizi gerçekleştirilmektedir. Mühendisler, mimarlar, bilim adamları ve planlamacılar, atmosferik hareketlerin hem yararlı hem de yıkıcı potansiyelini değerlendirmek için rüzgâr verilerinden yaygın olarak faydalanmaktadır (Balling, $\mathrm{Jr}$ ve Cerveny, 2005, s. 819).

Bölgesel ve yerel rüzgâr koşulları, termal konfor için doğal havalandırma sağlaması, kirlilik oluşumunu azaltması ve dış mekânların kullanımını iyileştirmesi yönüyle önemlidir. Bunlar 
dikkate alınmadığında sıcak veya soğuk hava akımları termal konforu olumsuz etkileyebilir. Farklı kaynaklarda oluşan gürültü ve/veya hava kirliliği rüzgârla uzun mesafelere taşınabilir ve yaşam kalitesinin bozulmasına yol açabilir. Ayrıca kuvvetli hava akımlarının neden olduğu sürtünme kuvveti, binaların dış cephesine zarar verebilir. Ortaya çıkabilecek olumsuzlukların önlenebilmesi için ortalama ve aşırı rüzgâr koşulları ile bunun hangi yönden etkili olduğu gibi konular da önem taşımaktadır (Loftness, 2005, s. 68). Rüzgâr hızındaki değişimin önceden bilinmesi ve bu değişimin miktarının tahmin edilmesi özellikle fırtınalar açısından da önem taşımaktadır. Fırtınalar, yol açtıkları can ve mal kayıpları nedeniyle önemlidir. Fırtınanın büyüklüğü ve tekrarlanma sıklıklarının araştırılması, özellikle enerji üretimi ve sigortacılık gibi ekonomik sonuçları olan iki temel faaliyet ile de yakından ilgilidir.

Rüzgârın bir diğer özelliği de enerji kaynağı olmasıdır. Rüzgâr enerjisinin kullanımına ilişkin ilk örnekler akarsu, göl, deniz gibi su üzerindeki taşıtların hareket ettirilmesine aittir. Teknolojik gelişmelere bağlı olarak rüzgârın kullanım alanları genişlemiş ve rüzgâr gücüyle çalışan değirmenlerden elektrik enerjisinin üretildiği rüzgâr tribünlerine kadar değişen uygulamalar ortaya çıkmıştır. Rüzgârdan elektrik üretimi açısından sadece rüzgârın estiği yön ve hızı değil, aynı zamanda rüzgâr yönü ile hızın ilişkisine göre belirlenebilecek olan rüzgârdan üretilecek/üretilebilecek enerji miktarı da önem kazanmaktadır. Bu nedenle "enerji gülü” olarak da tanımlanan ve hâkim rüzgâr yönünden farklı olabilen, en fazla enerjinin üretilebildiği yön veya yönleri gösteren “rüzgâr enerji gülü”nün hazırlanmas1 gerekmektedir (Türksoy, 2001, s. 97-98). Günümüzde rüzgârdan elektrik üretiminin payı yavaş, fakat düzenli olarak artmaktadır. Ekonomiye olan katkısı nedeniyle bu konudaki araştırmalar da son yıllarda önem kazanmıştır.

Etkilerinin çok farklı şekillerde gerçekleşmesi nedeniyle rüzgâr rasatları, yapılış amacına göre farklılık göstermektedir. Meteoroloji istasyonlarında rüzgâr yönü, gerçek kuzeye göre azimut değeri esas alınarak tanımlanmaktadır ve rasat süresi 10 dakikadır. Buna karşılık havacılıkta rüzgârdaki anlık değişim önemlidir. Bu nedenle uçak iniş ve kalkışı için havaalanlarında ölçme ve raporlama faaliyetleri manyetik kuzeye göre rüzgâr yönünü belirlemekte ve bu 2 dakikalık süreler ile tekrarlanmaktadır (CWOP-WMO8, 2008, s. I.5-2).

\section{AMAÇ VE YÖNTEM}

$\mathrm{Bu}$ çalışmanın temel amacı, hâkim rüzgâr yönünün ve frekansının belirlenmesinde kullanılabilecek Rubinstein yöntemine göre oluşturduğumuz PrevailingWindRUB 1.0 yazılımın bilim dünyasına tanıtılmasıdır. Çalışmada önce, farklı kaynaklara dayanarak hâkim rüzgâr yönünün belirlenmesinde kullanılan yöntemlerden bazılarına ver verilmiştir. Hâkim rüzgâr yönü ve frekansı ile varsa ikinci dereceden hâkim rüzgâr yönü ve frekansının gösterilebildiği Rubinstein yönteminin uygulanması çalışmanın ikinci bölümünde açıklanmıştır.

Rubinstein yönteminde kullanılan formüllere ait matematiksel işlemlerin hatasız olarak yapılması önem taşımaktadır. Çalışmanın ekinde Rubinstein yönteminin doğru ve kolay bir şekilde kullanılabilmesi için geliştirilen PrevailingWindRUB 1.0 isimli yazılım yer almaktadır. PrevailingWindRUB 1.0 ofis programlarına aşina temel kullanıcı için düzenlenmiştir. Söz konusu yazılım, Windows veya Linux ortamında herhangi bir ofis programının hesaplama arac1 [Microsoft Office - Excel (.xls veya .xlsx), LibreOffice - Calc Hesap Tablosu (.odt), Apache OpenOffice - Calc (.odt), Google E-Tablolar vb] ile çalışabilecek şekilde tasarlanmıştır. Programın içindeki hesaplamalar yerleşik fonksiyonlarla gerçekleştirilmektedir. $\mathrm{Bu}$ nedenle ayrıca oluşturulmuş makro içermemekte ve ayrı bir çalışma dosyası (.exe) gerektirmemektedir.

Program aylık, mevsimlik ve yıllık hâkim rüzgâr yön/ yönlerinin belirlenmesi amacıyla hazırlanmıştır. Aylık verilerin girilmesi halinde, sonuçlar kısmında hâkim rüzgâr yönleri aylara göre hesaplandığı gibi, mevsimlere göre ve yıllık toplam değerlerine göre de ortaya konulmaktadır. Veri girişinde herhangi bir aya veya yıllık toplam kısmına girilecek günlük veya belli bir zaman dilimine ait yönlerin esme sayılarından elde edilecek hâkim rüzgâr yönü, girilen sütuna göre sonuç sekmesinde yer alacaktır. Türkiye'de meteoroloji istasyonlarına ait rüzgâr yönü ve esme sayılarını içeren veri, Meteoroloji Genel Müdürlüğü’nden, diğer ülkelerin verisi ilgili ülkedeki kuruluştan edilmektedir.

\section{HÂKİM RÜZGÂR YÖNÜNÜN BULUNMASINDA KULLANILAN YÖNTEMLER}

Coğrafi inceleme, planlama gibi çalışmalarda rüzgârın hızı ile hangi yönde estiği yanında, belli bir zaman diliminde (gün, ay, mevsim veya yıl) hâkim rüzgâr yönü ve frekansının belirlenmesi büyük önem taşımaktadır. Rüzgâr yönünün belirlenmesi düşüncesinin temelinde, rüzgârın atmosferi hareket ettirmeye çalışan kuvvetler olarak kabul edilmesi yer almaktadır (Mayer, 1891, s. 112). Hâkim rüzgâr yönünün belirlenmesi ve gösteriminde temel olarak rüzgârın hangi yönden kaç kez estiği (frekansı) esas alınmaktadır. Bu nedenle en basit haliyle esme sayılarını esas alarak çizilen bir rüzgârgülü, hâkim rüzgâr yönü 
hakkında fikir verebilir. Hâkim rüzgâr yönünün belirlenmesi geometrik olarak gerçekleştirilebileceği gibi çeşitli formüller yardımıyla da hesaplanabilmektedir.

Hâkim rüzgâr yönünün ortaya konulmasında geometrik hesaplama yöntemi, bir rüzgârgülü oluşturulmasına ve kuzeyden itibaren saat istikameti yönünde rüzgârgülünün yan yana iki kolunun kuvvet bileşkesinin belirlenmesine dayanmaktadır. Yöntem Kaminsky tarafindan önerilmiştir (Kaminsky, 1925, s. 5-7). Yöntemde rüzgârgülünün kolları, esme sayıları ile orantılı olarak bir ölçeğe göre oluşturulmalıdır. Ancak önerilen yöntem, esme sayılarının çok düşük olduğu yönlerin gösteriminde güçlüklere neden olduğu gibi, gerçeği aksettirmede yetersiz de kalmaktadır. $\mathrm{Bu}$ nedenle fazla kullanım alanı bulamamıştır
(Allisow, Drostov ve Rubinstein, 1956, s. 473-474). Hâkim rüzgâr yönünün geometrik yöntemle belirlenmesine örnek olmak üzere; Adana meteoroloji istasyonunun 1975-2006 y1llarına ait yıllık rüzgâr frekans verisi kullanılarak rüzgârgülü oluşturulmuştur (Tablo 1; Şekil 1).

Rüzgârgülünün çizilmesinden (A) sonra, ikinci aşamada birbirine komşu iki yöne ait esme sayıları esas alınarak kuvvet bileşkesinin belirlenmesi için bir paralelkenar oluşturulur. $\mathrm{Bu}$ şekilde $\mathrm{N}$ ve $\mathrm{NE}, \mathrm{E}$ ve $\mathrm{SE}, \mathrm{S}$ ve $\mathrm{SW}$, W ve NW yönlerinin kenarlarının meydana getirdiği 4 paralelkenar ortaya çıkar. Ardından her paralelkenara ait kuvvetlerin bileşkeleri elde edilir (B). Üçüncü aşamada ortaya çıkan yeni kuvvet bileşkeleri kullanılarak, yine saatin dönüş yönünde, yeni paralelkenarlar

Tablo 1: Adana meteoroloji istasyonunun rüzgâr frekans tablosu (1975-2006).

Table 1: Wind frequency of Adana meteorological station (1975-2006).

\begin{tabular}{|c|c|c|c|c|c|c|c|c|}
\hline Yönler & $\mathbf{N}$ & NE & $\mathbf{E}$ & SE & $\mathbf{S}$ & SW & $\mathbf{W}$ & NW \\
\hline Esme sayısı & 7325 & 3376 & 2298 & 4708 & 5635 & 2461 & 1229 & 2734 \\
\hline
\end{tabular}

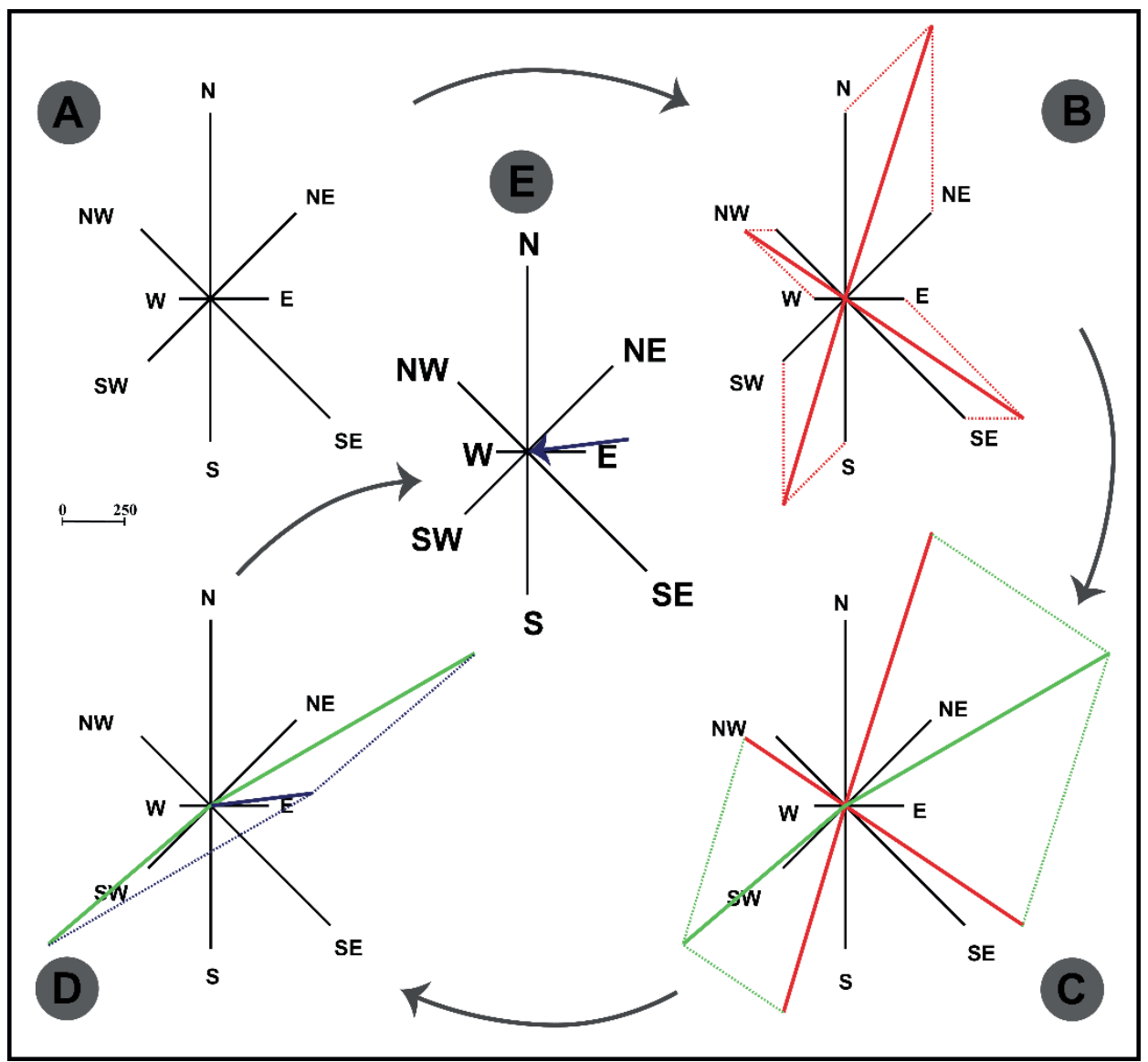

Şekil 1: Hâkim rüzgâr yönünün geometrik yöntemle belirlenmesi (A-Rüzgârgülü, B-8 yönün 4 yöne indirilmesi, C-4 yönün 2 yöne indirilmesi, D-2 yönün tek yöne indirilmesi, E-Adana'nın hâkim rüzgâr yönünün gösterilmesi).

Figure 1: Determining the prevailing wind direction by geometric method (A-Wind rose, B- 8 direction converted to 4 direction, $C$ - 4 direction converted to 2 direction, $D$ - 2 direction converted to 1 direction, $E$-Representation of the prevailing wind direction in Adana). 
oluşturulur (C). Bunun sonucunda 2 paralelkenar meydana gelir. Son olarak bu paralelkenardan elde edilen kuvvet bileşkesinden yeni bir paralelkenar çizilir (D). Paralelkenara ait kuvvetlerin bileşkesi bu yöntemle bulunan hâkim rüzgâr yönüne işaret etmektedir (E). Bu yöntemin olumsuz yönleri arasında; hesaplama sürecinin uzunluğu, hata yapma olasılığının yüksekliği gibi unsurları da saymak yerinde olacaktır.

Rüzgârgülü kullanarak hâkim rüzgâr yönünün belirlenmesinde sonuç, 8 veya 16 yöne göre ifade edilmektedir. Gerçekte ise hâkim rüzgâr yönü daha farklı olabilir. Hâkim rüzgâr yönünün açı cinsinde ortaya konulması, gerçeğe daha yakın sonuçları yansıtacaktır (Erinç, 1960, s. 1; Erinç, 1969, s. 459). Hâkim rüzgâr yönünün formül yardımıyla bulunması birçok araştırıcının ilgisini çekmiştir.

Bunlardan biri de Lambert'tir. Lambert tarafindan geliştirilen formülde de (Lambert, 1777, s. 26'ye atfen Kämtz, 1831, s. 164-165), 8 yöne göre rüzgârların esme sayıları kullanılmıştır. Lambert yazdığı formülünde, rüzgârın bir koordinat sistemi üzerinde gösterilebileceğini, koordinat sisteminde $\mathrm{x}$ (apsis) ekseninde (+) değerlerin kuzeyi, (-) değerlerin güneyi, y (ordinat) ekseninde $(+)$ değerlerin doğuyu, (-) değerlerin ise batıyı göstermek üzere kullanabileceğini düşünmüş ve trigonometrik fonksiyonlardan faydalanmıştır. Formül, $\tan \alpha=\frac{A}{B}$ şeklindedir. Rüzgârın ana yönlere $45^{\circ}$ 'lik açı ile geldiği ara yönlere ait rüzgâr esme sayıları ise, koordinat sisteminde bulundukları yarıma göre ya eklenmekte veya çıkartılmaktadır. Buna göre doğudan gelen rüzgârın esme sayısından batıdan gelen rüzgârın esme sayısı çıkartılır. Ancak batı yönün değeri, ara yönlere ait esme sayılarının da dâhil edildiği bir hesaplama ile belirlenir. Bu hesaplamada; doğudan esen rüzgârın esme sayısına kuzeydoğu ve güneydoğudan esen rüzgârların esme sayılarının eklenmesi, buna karşılık batı, kuzeybatı ve güneybatı rüzgârlarının esme sayılarının çıkartılması ve elde edilen sonucun da $\sin 45^{\circ}$ ile çarpılması gerekmektedir. Kuzey ve güneyden esen rüzgârlarda da benzer bir işlem uygulanır. Güneyden esen rüzgârın esme sayısından kuzeydoğu ve kuzeybatı yönlerinden esen rüzgârların esme sayıları eklenirken, güneydoğu ve güneybatıdan gelen rüzgârların esme sayıları çıkartılır. Çıkan değer ile $\cos 45^{\circ}$ ile çarpılarak güneyden esen rüzgârın esme sayısına eklenir. Buna göre formülde,

$$
\begin{aligned}
& A=E-W+(N E+S E-N W-S W) \cdot \sin 45^{\circ} \\
& B=N-S+(N E+N W-S E-S W) \cdot \cos 45^{\circ}
\end{aligned}
$$

eşitlikleri mevcuttur (Kämtz, 1831, s. 165). A ve B'nin değerleri yerine konulduğunda formülün son hali;

$$
\tan \alpha=\frac{E-W+(N E+S E-N W-S W) \cdot \sin 45^{\circ}}{N-S+(N E+N W-S E-S W) \cdot \cos 45^{\circ}}
$$

olmaktadır. Formülde yer alan $\sin 45^{\circ}$ ile $\cos 45^{\circ}$ birbirine eşittir ve sayısal karşıll $\breve{g ̆}_{1} \frac{\sqrt{2}}{2} \cong 0,707^{\prime}$ ye denk düşmektedir. Lambert'in hâkim rüzgâr yönünün bulunması için önerdiği formülün farklı kaynaklarda değişik şekillerde yer aldığı görülmüştür. Buna göre formül Ardel ve diğerleri tarafindan yapılan bir yayında (Ardel, Kurter ve Dönmez, 1969, s. 143);

$$
\tan \alpha=\frac{N-S+(N W+N E-S W-S E) \cdot \cos 45^{\circ}}{W-E+(N W+S W-N E-S E) \cdot \cos 45^{\circ}}
$$

şeklinde tanımlanırken, Kraght'ın yayınında ise;

$$
\tan \alpha=\frac{E-\left[W(N E+S E-N W-S W) \cdot \cos 45^{\circ}\right]}{N-\left[S(N E+N W-S E-S W) \cdot \cos 45^{\circ}\right]}
$$

şeklindedir (Kraght, 2005). Rüzgâr esme sayılarının düşük olduğu durumlarda formülün uygulanması ile doğru sonuca ulaşlabilmektedir. Zaman içinde formülün iyileştirilmesine yönelik bu girişimlere karşılık, rüzgâr esme sayılarının çok değişken olduğu durumlarda hataların meydana gelmesi, hâkim rüzgâr yönünün belirlenmesi ve ifadesinde yaşanan güçlükler bu formülün yaygınlaşmasını engellemiştir. Bulunan rüzgâr yönünün tanımlanmasında kuzey, kuzeydoğu ve kuzeybatı rüzgârlar kuzey sektörlü, kuzeydoğu, doğu ve güneydoğu yönlü rüzgârlar da doğu sektörlü rüzgârlar olarak ifade edilmektedir (Mayer, 1891, s. 112113). Buna göre güneydoğu, güney ve güneybatıdan esen rüzgârlar güney sektörlü; güneybatı, batı ve kuzeybatıdan esen rüzgârlar da batı sektörlü rüzgârlar olarak ifade edilebilir.

Rubinstein 1926 yılında yayınlanan çalışmasında, rüzgârın hangi yönden ne kadar sıklıkla estiği esas alınarak hâkim rüzgâr yönü derece cinsinden belirlenebileceğini ifade etmektedir (Rubinstein, 1926'ya atfen Allisow, Drostov ve Rubinstein, 1956, s. 474). Rubinstein yöntemiyle sadece hâkim rüzgâr yönü derece cinsinden değil, aynı zamanda yüzde olarak frekansının da bulunması (Ardel, Kurter ve Dönmez, 1969, s. 145) bu formülün yaygınlaşmasını sağlamıştır. Bazı yazarlar tarafından esme sayıları esas alınarak yapılacak hesaplamalarda, kullanılan sayının diğer sayılar ile karşılaştırılmasında sorun olduğuna işaret edilmektedir (Schouw, 1827, s. 8-9). Bu durum eşit olmayan aylar ile eşit olmayan y1llara ait değerlerin 
karşılaştırılmasında da ortaya çıkmaktadır. Rubinstein'in önerdiği yöntemde, toplam esme sayıları değil, her yöne ait esme sayılarının toplam içindeki oranı kullanılmaktadır. $\mathrm{Bu}$ işlemi yaparken aynı zamanda farklı yönlere ait paylar ile de belli ilişkilerin göz önüne alınması, yöntemi diğer yöntemlere nazaran daha avantajlı hale getirmektedir. Yöntemde sakin günlere ait veriler ise kullanılmamaktadır. Sakin günlere ait verilerin hâkim rüzgâr yönünün belirlenmesinde karışıklığa neden olduğu için hesaplamaya dâhil edilmemesi, ihtiyaca göre ayrıca hesaplanması gerektiği Kaminsky tarafından da ifade edilmektedir (Allisow, Drostov ve Rubinstein, 1956, s. 472).

Rubinstein yönteminde hâkim rüzgâr yönü;

$$
x_{\text {max }}=1+\frac{n 3-n 1}{(n 3-n 1)+(n 2-n 4)}
$$

formülüyle ortaya konurken, frekansı ise;

$\varphi_{\left(x_{\max }\right)}=n 2+n 3+\frac{(n 3-n 1)+(n 2-n 4)}{2} \cdot\left(\frac{3}{2}-x_{\max }\right)^{2}$

eşitliğiyle bulunmaktadır (Allisow, Drostov ve Rubinstein, 1956, s. 474-477). Formüllerde $x_{\max }$, hâkim rüzgâr yönünü, n1, n2, $\mathrm{n} 3$ ve $\mathrm{n} 4$ ise dizi elemanlarını göstermektedir.

Rubinstein yöntemine göre hâkim rüzgâr yönünün bulunmasında saatin dönüş istikametinde birbiri ardı sıra gelen yönlere ait frekansların yüzdelerinin belli özelliklere sahip bir dizi oluşturması beklenir. Buna göre dizinin üçüncü terimi, birinci terimden, ikinci terimi ise dördüncü terimden büyük, ikinci ve üçüncü terimlerin toplamı en az \%25 olmalıdır.

Bu koşulları sağlayan bir dizi oluşturulabiliyorsa tek hâkim rüzgâr yönünden, ikinci bir dizi oluşuyorsa ikinci dereceden hâkim rüzgâr yönünün varlığından söz edilebilir. Diziler oluşturulduktan sonra, her dizide yer alan terimlerin toplam frekans içindeki yüzdeleri formüllerde yerine konur ve hâkim rüzgâr yönü ile frekansı belirlenir. İki dizinin oluştuğu örneklerde frekansı daha yüksek olan dizi hâkim rüzgâr yönünü göstermektedir.

\section{RUBINSTEIN YÖNTEMINE GÖRE HÂKIM RÜZGÂR YÖNÜNÜN BELIRLENMESİ}

Rubinstein yönteminde yukarıda belirtilen diğer yöntemlerde olduğu gibi hâkim rüzgâr yönünün belirlenmesinde, belli yönde esen rüzgârın eşiş sıklığından (frekansından) yararlanılmaktadır. 8 yöne göre hazırlanan rüzgâr frekans tablosunun birinci satırında yönler, ikinci satırında esme sayıları, üçüncü satırında ise toplam esiş miktarındaki oranları yer alır. Yukarıda da belirtilen; n3>n1, n2>n4 ve n2+n3 $\geq \% 25$ koşulu, her yön için ayrı ayrı aranarak dizi veya dizilerin oluşup oluşmadığı kontrol edilir. Oluşan dizilerin elemanları formülde yerine konularak hâkim rüzgâr yönü/yönleri ve frekansı/frekansları tespit edilir (Ardel, Kurter ve Dönmez, 1969, s. 145; Dönmez, 1979, s. 126 vd.; Erinç, 1969, s. 459 vd.).

Adana meteoroloji istasyonunun 1975-2006 dönemine ait rüzgâr esme sayıları örnek olarak kullanılmıştır (Tablo 2). Örnekte dizi başlangıcı olarak kuzey kullanıldığında kuzeyden esen rüzgâr (n1) doğudan esen rüzgârdan (n3) büyük olduğu için bir dizi oluşturmaz. Bu durumda ikinci yön olan kuzeydoğunun bir dizi başlangıcı olup olmayacağı araştırılır. Kuzeydoğudan esen rüzgâr (n1) güneydoğudan esen rüzgârın (n3) yüzdesinden küçük olmasına karşılık, doğudan (n2) esen rüzgâr, güneyden esen rüzgârdan (n4) büyük olmadığı için yine bir dizi meydana gelmemektedir. Doğudan esen rüzgârın dizi başlangıcı (n1) olarak atandığı durumda; güneyden esen rüzgârın (n3) doğudan esen rüzgârdan, güneydoğudan esen rüzgârın (n2) güneybatıdan esen rüzgârdan (n4) fazla esme sayısına sahip olduğu, güneydoğudan (n2) ve güneyden (n3) esen rüzgârların esme sayılarının toplama oranı da $\% 34,7$ olduğu için bir dizi oluşmaktadır (3. satır).

Dizinin oluşmasından sonra, diğer yönlerde de yeni bir dizinin oluşup oluşmadığına mutlaka bakmak gerekir. Bir dizinin gerçekleşmesi, bu dizinin hâkim yön olduğu anlamına da gelmemektedir. Örnekte güneydoğu, güney, güneybatı ve batı yönlerinin dizi başlangıcı olarak belirlenmesi halinde kuralların gerçekleşmediği, buna karşılık kuzeybatı yönünün dizi başlangıcı olarak atanması durumunda yine koşulların sağlandığı

Tablo 2: Adana meteoroloji istasyonu verilerine göre 8 yöne ait rüzgâr esme sayıları ve yüzdeleri (1975-2006)

Table 2: Wind blowing numbers and percentages according to 8 directions in Adana meteorological station data (1975-2006).

\begin{tabular}{|c|c|c|c|c|c|c|c|c|c|}
\hline Adana & $\mathbf{N}$ & NE & $\mathbf{E}$ & SE & $\mathbf{S}$ & SW & $\mathbf{W}$ & NW & Toplam \\
\hline Esme sayısı & 7325 & 3376 & 2298 & 4708 & 5635 & 2461 & 1229 & 2734 & 29766 \\
\hline$\%$ & 24,6 & 11,3 & 7,7 & 15,8 & 18,9 & 8,3 & 4,1 & 9,2 & \\
\hline Dizi 1 & & & $\mathrm{n} 1$ & $\mathrm{n} 2$ & n3 & $\mathrm{n} 4$ & & & \\
\hline Dizi 2 & $\mathrm{n} 2$ & n3 & $\mathrm{n} 4$ & & & & & $\mathrm{n} 1$ & \\
\hline
\end{tabular}


görülmektedir (4. satır). Bu Adana meteoroloji istasyonunda iki dizinin oluştuğunu, bunlardan birinin başlangıcının doğu (E), diğerinin ise kuzeybatı (NW) olduğunu göstermektedir.

Bundan sonraki aşamada her iki diziye ait değerler sırası ile formüldeki yerlerine konulur. Buna göre 3. satırdaki dizinin değerleri

$$
\begin{gathered}
x_{\max }=1+\frac{n 3-n 1}{(n 3-n 1)+(n 2-n 4)} \\
x_{\max }=1+\frac{18,9-7,7}{(18,9-7,7)+(15,8-8,3)} \\
x_{\max }=1+\frac{11,2}{(11,2)+(7,5)} \\
x_{\max }=1+\frac{11,2}{18,7} \\
x_{\max }=1+0,598 \\
x_{\max }=1,598
\end{gathered}
$$

Hakim rüzgâr yönünü belirlemek için kullanılan 8 yönün arasında $45^{\circ}$ lik açı olduğu için elde edilen değer, 45 ile çarpılarak hakim rüzgâr yönünün açı cinsinden değeri bulunur. Buna göre $45 \times 1,598=71,9$ olduğundan 3. satırda yer alan dizideki rüzgâr, doğu (n1) ile saat ibresinin dönüş yönünde $71,9^{\circ}$ lik açı yaptı̆̆ı sonucuna ulaşılmaktadır.
Örnekte ikinci bir dizi meydana gelmiştir. 4. satırdaki bu diziye de aynı formül uygulanır.

$$
\begin{gathered}
x_{\max }=1+\frac{n 3-n 1}{(n 3-n 1)+(n 2-n 4)} \\
x_{\max }=1+\frac{11,3-9,2}{(11,3-9,2)+(24,6-7,7)} \\
x_{\max }=1+\frac{2,1}{(2,1)+(16,9)} \\
x_{\max }=1+\frac{2,1}{19,0} \\
x_{\max }=1+0,110 \\
x_{\max }=1,110
\end{gathered}
$$

Çıkan sonucun $45^{\circ}$ ile çarpılmasılyla elde edilen $49,9^{\circ}$ değeri, rüzgâr yönünün dizi başlangıcının (n1) olduğu kuzeybatı ile saat ibresinin dönüş yönünde $49,9^{\circ}$ 'lik açıya sahip olduğunu göstermektedir (Şekil 2).

Bulunan bu değerler, Adana'da biri birinci derecede, diğeri ise ikinci derecede olmak üzere iki hâkim rüzgâr yönü bulunduğunu ortaya koymaktadır. İki değerden hangisinin birinci derecede hâkim rüzgâr yönünü, hangisinin ise ikinci dereceden hâkim olduğunu belirlemek için ikinci formül kullanılmaktadır. $\mathrm{Bu}$ formülde meydana gelen dizinin toplam içindeki payı bulunmaktadır. Formülde 3. satırdaki dizinin değerleri yerlerine konulduğunda;

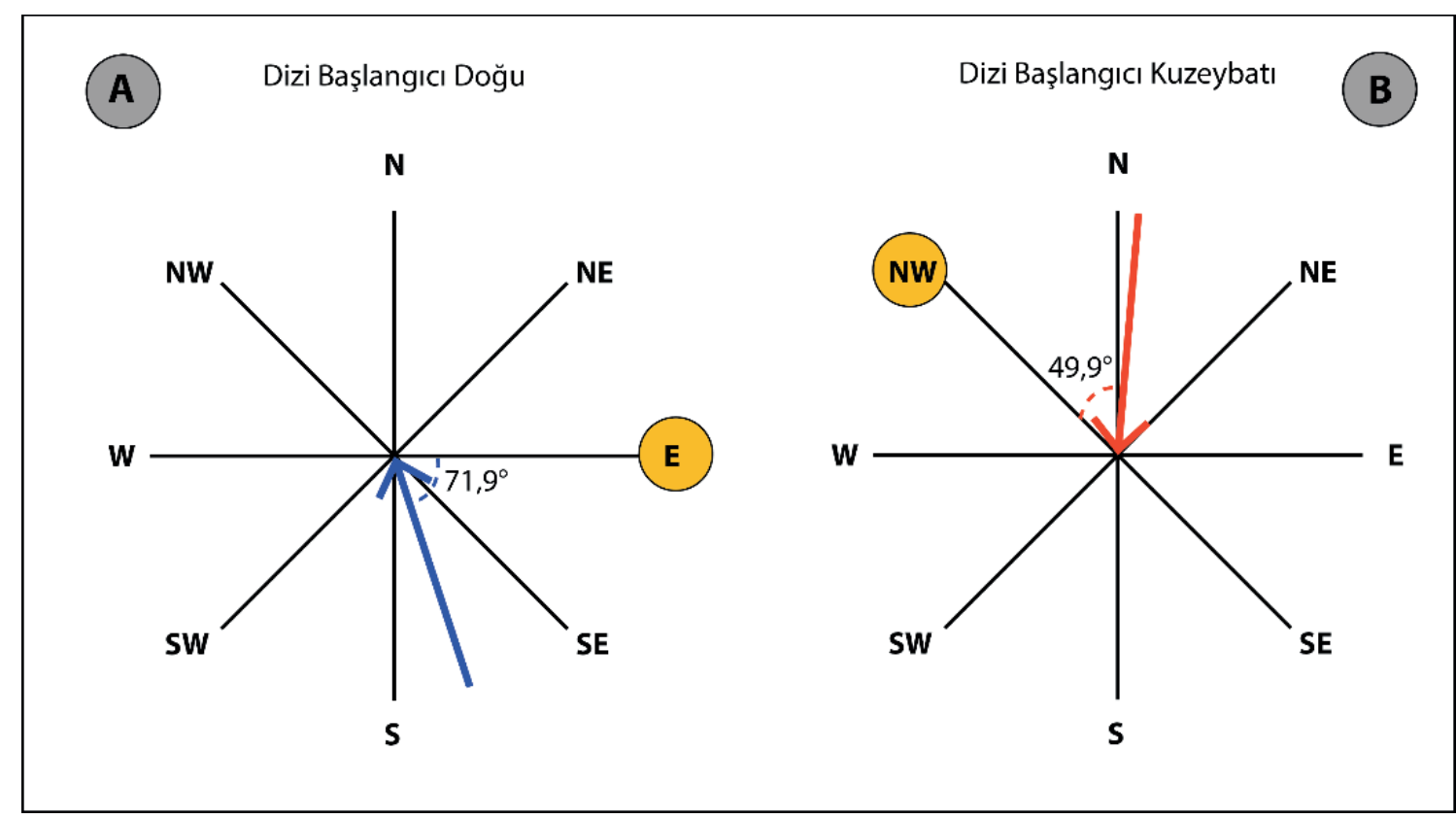

Şekil 2: Adana meteoroloji istasyonunun birinci ve ikinci dereceden hâkim rüzgâr yönü ve frekansı Figure 2: First and second-degree prevailing wind direction and frequency of Adana meteorological station. 


$$
\begin{gathered}
\varphi\left(x_{\max }\right)=n 2+n 3+\frac{(n 3-n 1)+(n 2-n 4)}{2} \cdot\left(\frac{3}{2}-x_{\max }\right)^{2} \\
\varphi\left(x_{\max }\right)=15,8+18,9+\frac{(18,9-7,7)+(15,8-8,3)}{2} \cdot\left(\frac{3}{2}-1,598\right)^{2} \\
\varphi\left(x_{\max }\right)=34,7+\frac{(11,2)+(7,5)}{2} \cdot\left(\frac{3}{2}-1,598\right)^{2} \\
\varphi\left(x_{\max }\right)=34,7+\frac{(18,7)}{2} \cdot(1,5-1,598)^{2} \\
\varphi\left(x_{\max }\right)=34,7+9,35 \cdot(-0,098)^{2} \\
\varphi\left(x_{\max }\right)=34,7+9,35 \cdot 0,009604 \\
\varphi\left(x_{\max }\right)=34,7+0,0897 \\
\varphi\left(x_{\max }\right)=34,789 \\
\varphi\left(x_{\max }\right)=34,8
\end{gathered}
$$

Aynı formül 4. satırdaki değerlere uygulandığında;

$$
\begin{gathered}
\varphi\left(x_{\max }\right)=n 2+n 3+\frac{(n 3-n 1)+(n 2-n 4)}{2} \cdot\left(\frac{3}{2}-x_{\max }\right)^{2} \\
\varphi\left(x_{\max }\right)=24,6+11,3+\frac{(11,3-9,2)+(24,6-7,7)}{2} \cdot\left(\frac{3}{2}-1,11\right)^{2} \\
\varphi\left(x_{\max }\right)=35,9+\frac{(8,1)+(16,9)}{2} \cdot\left(\frac{3}{2}-1,11\right)^{2} \\
\varphi\left(x_{\max }\right)=35,9+\frac{25,0}{2} \cdot(1,5-1,11)^{2} \\
\varphi\left(x_{\max }\right)=35,9+12,5 \cdot(0,387)^{2} \\
\varphi\left(x_{\max }\right)=35,9+12,5 \cdot 0,1497 \\
\varphi\left(x_{\max }\right)=35,9+1,87125 \\
\varphi\left(x_{\max }\right)=37,77 \\
\varphi\left(x_{\max }\right)=37,8
\end{gathered}
$$

sonucuna ulaşılır. Buna göre 3. sırada yer alan dizinin frekansı $\% 34,8$; 4. sırada yer alan dizinin frekansı ise \%37,8 $\mathrm{dir}$.

Hâkim rüzgâr yönü Rubinstein formülüne göre, kuzey veya güney yönünün doğusu veya batısında bulunuşuna göre tanımlanmaktadır. Buna göre 4. sırada yer alan dizinin frekansı daha yüksek olduğu için hâkim rüzgâr yönünü meydana getirmektedir. Dizi başlangıcını oluşturan kuzeybatı yönünden saatin dönüş yönünde 49,9lik bir açı yapmaktadır. Kuzeybatı $(\mathrm{NW})$ ve kuzey $(\mathrm{N})$ yönleri arasındaki açı değerinin $45^{\circ}$ olduğu göz önünde bulundurulursa, rüzgârın esiş yönü aradaki fark kadar $\left(4,9^{\circ}\right)$ kuzeyin doğusunda yer alacaktır. 3. satırda yer alan dizi, frekansı daha düşük olduğu için ikinci dereceden hâkim rüzgâr olarak tanımlanmaktadır. Rüzgârın yönü, doğudan 71,9 uzaktadır. Bu söz konusu rüzgârın güney sektörlü olduğunu gösterir. İfade edilirken güney (S) yönüne göre tanımlanması gerekir. Doğu ve güney yönleri arasındaki açı değeri $90^{\circ}$ ' dir. $\mathrm{Bu}$ açı değerinden $71,9^{\circ}$ çıkartıldığında, rüzgârın güneyden (S) ne kadar uzakta olduğu bulunur. Bu değer de 18,1 ' dir. Adana'nın hâkim rüzgâr yönü ifadesi; “'Adana'nın birinci dereceden hâkim rüzgâr yönü \%37,8 frekansla $\mathrm{N} 4,9^{\circ} \mathrm{E}$ 'dan, ikinci dereceden hâkim rüzgâr yönü \%34,8 frekansla S $18,1^{\circ} \mathrm{E}$ 'dan esmektedir" şeklindedir (Şekil 3).

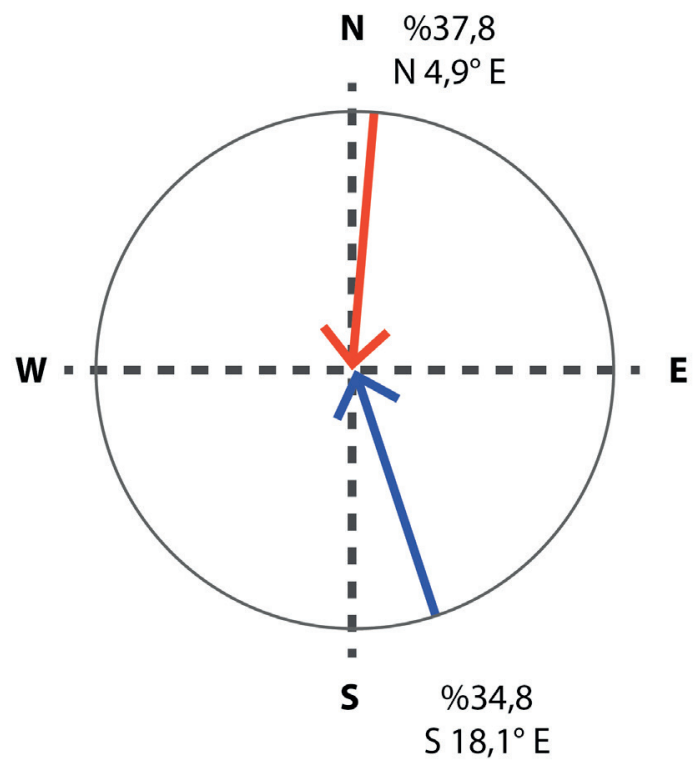

Şekil 3: Adana meteoroloji istasyonu verilerine göre hâkim rüzgâr yönleri (1975-2006).

Figure 3: Prevailing wind directions in Adana (1975-2006).

\section{PrevailingWindRUB 1.0'IN KULLANIMI}

Meteoroloji istasyonlarının rüzgâr verisi, günümüzde genellikle 16 yöne göre verilmektedir. $\mathrm{Bu}$ durumunda esme sayılarının PrevailingWindRUB 1.0'1n Data (Veri) sekmesindeki ilgili yönlere girilmesi gereklidir ve program verinin 8 yöne dönüştürülmesini gerçekleştirecektir. Eğer mevcut veri 8 yöne ait ise bu verinin ikinci tabloya işlenmesi yeterlidir. Hâkim rüzgâr yönünün bulunması için aylık veya yıllık rüzgâr esme sayıları girilebilir. Aylık verilerin girilmesi durumunda Result (Sonuç) sekmesinde aylık, mevsimlik ve yıllık hâkim rüzgâr yönü veya yönleri, sadece y1llık verilerin girilmesi durumunda da yıllık hâkim rüzgâr yönü veya yönleri yer alacaktır. Grafikler, “G” ile başlayan sekmelerdedir. G_1 ... G_12 aylık ortalamalara göre hâkim rüzgâr yönü/yönlerini; G_Annual, yıllık ortalamalara göre hâkim rüzgâr yönü/yönlerini; G_Winter K1ş, G_Spring İlkbahar, G_Summer, Yaz ve G_Autumn Sonbahar mevsimindeki ortalamalara göre hâkim rüzgâr yönü/yönlerini göstermektedir. Grafikleri hesaplama dosyasından kopyalarak kelime işlemci, vektörel bir program veya resim işleyiciye yapıştırarak üzerinde değişiklik yapmak mümkündür.

Sonuçlar doğrudan \% cinsinden frekansı ve rüzgârın kuzey ve güney yöne doğu veya batıdan geliş açısını vermektedir. PrevailingWindRUB 1.0 yazılımı ile Adana meteoroloji istasyonunun birinci dereceden hâkim rüzgâr yönü \%37,4 frekansla $\mathrm{N} 5,1^{\circ} \mathrm{E}$, ikinci dereceden hâkim rüzgâr yönü \% 34,8 frekansla $\mathrm{S} 18,1^{\circ} \mathrm{E}$ olarak bulunmuştur. 


\section{SONUÇ}

Rüzgâr, bir enerji kaynağı olması yanında şehirsel ve kırsal alanların planlamasına, konut alanlarının veya sanayi tesislerinin yerinin belirlenmesine, ulaşım araçlarının yapımından güvenle kullanılmasına kadar farklı konularda gözönünde bulundurulması gereken önemli bir değişkendir. Rüzgârın geçmişte üstlendiği rol günümüzde yenileriyle genişlemektedir. Buna emisyon kaynaklarının konumlandırılması, böcek veya hastalıkların bir yerden başka bir yer taşınması ve hatta binaların havalandırılması ve doğrudan elektrik enerjisi üretimi gibi konular da eklenmiştir. Rüzgârın yönü, hızı ve frekansı rüzgârdan en yüksek düzeyde faydalanabilmek için gerekli unsurlardır. Rüzgârın esme sayısının en yüksek olduğu yönü oluşturan hâkim rüzgâr yönünün belirlenmesinde çeşitli yöntemler kullanılmakla beraber, formüle dayanan yöntemler daha çabuk ve doğruya yakın sonuçlar vermektedir.

Her ne kadar rüzgâr rasatları 8 veya 16 yön esas alınarak yapılıyorsa da hâkim rüzgâr yönü bu yönlerin dışında farklı bir açı ile gelmektedir. Formüle dayanarak hâkim rüzgâr yönünün belirlenmesinin avantajlarının başında bu yönlere bağlı kalmaksızın rüzgârın geliş açısı ile ifade edilebilmesi gelmektedir. Kullanılan formüller arasında Rubinstein tarafından önerileni, hâkim rüzgâr yönünün belirlenmesinde sadece en çok esen rüzgâr yönünü değil, diğer yönleri de hesaplamaya dâhil etmesi, karşılaştırılabilirlik açısından önemli olan esme sayılarını değil, bu sayıların toplam içindeki payını kullanması ile diğerlerinden ayrılmaktadır. Ayrıca varsa ikinci dereceden hâkim rüzgâr yönünü de göstermesi ve hâkim rüzgâr yön/yönlerinin yüzdelerini de belirlemesi Rubinstein'ın bu yöntemini öne çıkarmaktadır.

Rubinstein formülü bir dizi matematiksel işlemin sonunda hâkim rüzgâr yönünü belirlemektedir. Rubinstein formülünün matematiksel işlemleri, hatalı sonuca varmamak için azami dikkat istemektedir. Tam sayılardan oluşan rüzgâr esme sayısının formülde kullanımında ondalık sayılardan oluşan toplam esme sayısındaki payı esas alınmaktadır. Elle yapılan işlemlerde ondalık sayılar 1 veya 2 basamak ile gösterilmekte veya yuvarlama işlemi gerçekleştirilmektedir. Bu durum özellikle birden fazla işlemin artarda yapıldığı ve çıkan sonuçların farklı yerlerde yeniden kullanıldığı durumlarda sonucun değişmesine neden olabilir. Oysa bilgisayar ile yapılan işlemlerde sayıların gerçek değerleri kullanılabilmektedir.

Makalenin ekinde sunulan PrevailingWindRUB 1.0 isimli yazılım, veri girişinden sonra hızlı ve hatasız olarak hesaplamaları gerçek sayılar ile gerçekleştirmektedir ve hâkim rüzgâr yönünün belirlenmesine yönelik ihtiyacı karşılayacak özelliklere sahiptir.

Hakem Değerlendirmesi: Dış bağımsız.

Çıkar Çatışması: Yazar çıkar çatışması bildirmemiştir.

Finansal Destek: Yazar bu çalışma için finansal destek almadığını beyan etmiştir.

Teşekkür: Yazar, makale hakkındaki görüşlerini paylaşan Prof. Dr. İlhan Kayan'a ve Prof. Dr. Meral Avcı'ya, yapıcı eleştirilerinden dolayı hakemlere teșekkür eder.

Peer-review: Externally peer-reviewed.

Conflict of Interest: The author has no conflict of interest to declare.

Grant Support: The author declared that this study has received no financial support. Acknowledgment: The author thanks Prof.Dr. İlhan Kayan and Prof.Dr. Meral Avc1 for sharing their views on the article, and the referees for their constructive criticism.

\section{EK/SUPPLEMENT}

https://doi.org/10.5281/zenodo.4396127

https://cdn.istanbul.edu.tr/file/JTA6CLJ8T5/65682733DC 71487CAF6D8A6BCA1946A3

\section{KAYNAKCA/REFERENCES}

Allisow, B. P., Drostov, O. A., \& Rubinstein, E. (1956). Lerhbuch Der Klimatologie. Berlin: VEB Deutscher Verlag Der Wissenschaften.

Ardel, A., Kurter, A., \& Dönmez, Y. (1969). Klimatoloji Tatbikatt. İstanbul: İstanbul Üniversitesi Coğrafya Enstitüsü.

Avcı, M. (1998). Ilgaz dağları ve çevresinin bitki coğrafyası I (Bitki örtüsünün coğrafi şartları). İstanbul Üniversitesi Coğrafya Bölümü Coğrafya Dergisi, 137-216.

Avc1, M. (2016). Ekosistem Coğrafyasl. İstanbul: İstanbul Üniversitesi Açık ve Uzaktan Öğretim Fakültesi.

Balley, W. G. (2005). Microclimatology. J. E. Olivier içinde, Encylopedia of World Climatology (s. 486-499). Dordrecht, Berlin, Heidelberg, New York: Springer.

Balling, Jr, R. C., \& Cerveny, R. S. (2005). Winds and wind systems. J. E. Oliver (Dü.) içinde, Encyclopedia of World Climatology (s. 813819). Dordrecht, The Netherlands: Springer.

CWOP-WMO8. (2008). Guide to Meteorological Instruments and Methods of Observation. Geneva: World Meteolorlogical Organization.

Dönmez, Y. (1979). Umumi Klimatoloji ve İklim Çalışmaları. İstanbul: İstanbul Üniversitesi Coğrafya Enstitüsü.

Erinç, S. (1960). Türkiye'de zemine yakın hava tabakalarında hâkim rüzgâr istikametleri ve frekansları. İstanbul Üniversitesi Coğrafya Enstitüsü Dergisi, 1-11.

Erinç, S. (1969). Klimatoloji ve Metodları. İstanbul: İstanbul Üniversitesi Coğrafya Enstitüsü Yayını.

Erol, O. (1999). Genel Klimatoloji. İstanbul: Çantay Kitabevi.

Kaminsky, A. A. (1925). Klimat i pogoda v ravninnoy mestnosti - Klimat Voronezhskoy Gubernii. Leningrad: Novaya Derevnya. 
Kämtz, L. F. (1831). Lehrbuch der Meteorologie (Cilt 1). Halle.

Kraght, P. E. (2005). Wind and air velocity measurements. G. D. Considine içinde, Van Nostrand's Scientific Encylopedia. John Wiley and Sons. doi:10.1002/0471743984.vse7534.

Lamb, H. H. (2011). Climate: Present, Past and Future (Cilt 1: Fundemantals and Climate Now). Oxford: Routledge Revivals.

Lambert, M. (1777). Sur Les Observations du Vent. Nouveaux mémoires de l'Académie Royale des Sciences et Belles-Lettres, avec l'histoire (s. 36-41). içinde Berlin: Königliche Akademie der Wissenschaften.

Langreder, W. (2010). Wind resource and site assessment. W. Tong içinde, Wind Power Generation and Wind Turbin Design (s. 49-87). Southampton, Boston: WIT Press.

Loftness, V. (2005). Architecture and Climate. J. E. Olivier (Dü.) içinde, Encylopedia of Word Climatology (s. 63-77). Dordrecht, Berlin, Heidelberg, New York: Springer.

Mayer, H. (1891). Anleitung zur Bearbeitung meteorologischer Beobachtungen für die Klimatologie. Berlin: Verlag von Julius Springer.
Munro, D. S. (2005). Katabatic (gravity) winds. J. E. Olivier içinde, Encylopedia of World Climatology (s. 440). Dordrecht, Berlin, Heidelberg, New York: Springer .

Olivier, J. E. (2005). Local winds. J. E. Olivier içinde, Encylopedia of World Climatology (s. 467-475). Dordrecht, Berlin, Heidelberg, New York: Springer.

Rubinstein, E. (1926). Kmetodike klimatoloricheskoyobrabotki iablyudeniy nad vetrom (Zur methodik der klimatologischen Bearbeitung der Wildbeobachtungen). Iav. Tsentr. gidrometeorol. byuro.

Schouw, J. F. (1827). Beiträge Zur Vergleichenden Klimatologie. Kopenhagen: Verlag des Verfasser.

Thompson, R. D., \& Perry, A. (1997). Applied Climatology (Principles and Prectice). London ve New York: Routledge.

Tong, W. (2010). Fundamentals of wind energy. W. Tong (Dü.) içinde, Wind Power Generation and Wind Turbin Design (s. 3-48). Southampton, Boston: WIT Press.

Türksoy, F. (2001). Rüzgar verisi ölçümü ve analizi. Rüzgar Enerjisi Sетроzуити (s. 87-103). İzmir: TMMOB, Makina Mühendisleri Odası İzmir Şubesi. 
